\title{
FORÇA DA LEI E O PROJETO DE DECLÍNIO DA ORDEM SIMBÓLICA
}

\section{LAW ENFORCEMENT AND THE PROJECT OF DESCENT OF THE SYMBOLIC ORDER}

\author{
Aldacy Rachid Coutinho
}

Aos amigos os favores, aos inimigos a lei. Maquiavel Aos meus amigos, tudo! Aos inimigos,os rigores da lei! Getúlio Vargas

\section{Resumo}

Este artigo trata do registro simbólico da força da lei, independentemente da verificação da sua efetividade. 0 direito do trabalho revela nos marcos regulatórios a correlação de forças na sociedade de capital e trabalho e desta forma é exemplar para a constatação da existência de leis que não têm nenhum efeito na mudança da realidade. 0 reconhecimento de que o Estado cria leis que não são observadas e que não se pretende sejam cumpridas, não afasta a presença da violência da autoridade que institui uma ordem simbólica.

Palavras-Chave: Lei. Simbólico. Força.

\begin{abstract}
This article deals with the registration of the symbolic force of the law, regardless the verification of their effectiveness. The labor law reveals in his regulatory frameworks the correlation of forces of capital and labor in society and thus is exemplary for establishing the existence of laws that have no effect in changing the reality. The recognition that the state creates laws that are not observed and that it is not intended to be fulfilled, does not put away the presence of the authority by violence that establish a symbolic order.
\end{abstract}

Keywords: Law. Symbolic. Enforcement. 


\section{INTRODUÇÃO: O FETICHE DA LEI}

Tem-se que a lei ${ }^{1}$ representa por excelência, na sua autonomia, a presença imprescindível da institucionalização e estabilização de uma "ordem" social, econômica, política e jurídica reveladora de um "sistema" jurídico. Exprime, nesse trilhar, a força da autoridade do Estado ao impor, em um dado tempo e espaço, um padrão de normatividade, caracterizado no dever ser pela coerção, pela imperatividade, pela inafastabilidade de seu comando. Tal ordem jurídica caracterizar-se-ia, por "dizer o que se deve fazer, o que se deve ser e não constatar o que é" (MIAILLE, 1979, p. 82).

Outrossim, afirma-se a necessidade de se abandonar o "mito da eficácia transcendente da lei diante de sua permanente contestação encontrada na realidade social objetiva" (BARRETO, 2010, p. 7). É indubitável que a produção da lei, como ato de força, não é condição suficiente para seu cumprimento. Não sendo o direito uma esfera isolada e desconexa do mundo concreto a que faz referência, as razões pelas quais a submissão e a obediência - à lei por todos, enquanto texto gráfico que contém uma norma jurídica, se faz realidade concreta, se por pressupostos jurídicos ou não, se por medo da ameaça de um mal, ou para conquista de um bem, ou se por "exigência incondicionada ou categórica de sua aplicação" (ASCENSÃO, 2011, p. 38) captada pela consciência dos sujeitos, por um dever moral ou qualquer outra razão, ainda que seja inconsciente ou irracional é, para a análise jurídica sobre a sua existência, validade e eficácia, considerada como um indiferente.

A fé no poder da lei é tomada como um "fetiche", assim considerado como um objeto ao qual são atribuídas virtudes extraordinárias (MIAILLE, 1979, p.82) tal qual a mercadoria em Marx (MARX, 2002, p. 94). Com esse seu caráter misterioso que provém da sua forma, disfarçada em democracia e representatividade, reafirma enquanto fenômeno o caráter social e assume a forma de relação social. Através de dissimulação adquire propriedades perceptíveis aos sentidos, ocultando as relações materiais nela subjacentes: "Nisso se transformam, em certas explicações, palavras ou termos que teriam a virtude de fazer compreender, de explicar por si mesmos" (MIAILLE,1979, p. 82). Ela tem por escopo estabelecer marcos regulatórios que fixam comportamentos para o presente e para o futuro, 
procurando induzi-los segundo um padrão ideal tomado como desejável (GEBARA, 1986, p. 13); é crença, fé, aposta. Neste trilhar não existiriam leis inócuas; sempre haverá a marca da sua presença.

Para além de se constituir como um ato de autoridade pública, expressão de força e domínio de um Estado interventor, a lei explicita também, por certo, uma função hegemônica: o poder de uma elite, entabulando um mecanismo de reforço ou manutenção da hegemonia da classe dominante, definida enquanto tal pelo lugar ocupado dentro do processo produtivo (ARON, 2003, p. 628) em um momento histórico e diante de específica condição política (GEBARA, 1986, p. 12). As classes se expressam nas formas da lei (LAMOUNIER, 1988, p.17). Estado e classe dominante se constituem e se apresentam, então, como manifestações de uma mesma realidade: "Enquanto um Estado subsiste, ele aplicará e terá de aplicar o aparato legal a serviço da classe dominante". (STUTCHKA, 2001, p.89). Tal constatação explicaria a própria existência da lei, a dinâmica de sua produção; mas se assim é, poder-se-ia pensar que se instala, de outra parte, uma contradição percebida pelo seu não cumprimento, pois como sustentar nessa hipótese a força de uma autoridade estatal e a hegemonia da classe dominante, se leis editadas simplesmente não são aplicadas? Estar-se-ia atribuindo às elites uma insinceridade ou um desprezo transposto em racionalidade cínica e hipócrita identificada na inocuidade de preceitos legais?

Canalizando as expectativas “[...] é a aquiescência e a submissão que fazem da lei um efetivo instrumento para se obter o controle social e tornar possível a implementação de um projeto político ordenado pelos que têm a capacidade e poder de elaborar a própria lei” (GEBARA, 1986, p. 16). Em ilusão, a lei enquanto narrativa discursiva declara e constitui o social, espaço no qual os conflitos se externalizam, ganhando materialidade na abstração e concretude na imperatividade de uma violência real e simbólica.

Seu mistério reflete, então, ao mesmo tempo a verdade e a ilusão - por ocultação - das relações humanas no modelo capitalista de mercado: "é porque a sociedade não tem consciência da base da sociedade em que vive que os capitalistas e os economistas burgueses são vítimas das ilusões" (ARON, 2003, p. 303). Ideologicamente, o direito, instituindo formas de 
relações entre classes e sendo assim, ao mesmo tempo instituído e instituidor, exerce sua função de legitimação, não podendo ser pensado somente como dissimulação, senão igualmente como "conforto" (RICOUER, 2015, p. 16). A lei define e é definida exatamente como mediação de ideais neste campo de relações intersubjetivas. Merece ser vista no mundo 'vivido', na concretude repleta e tomada por múltiplos significados e valores.

Ocorre que a lei igualmente mediatiza e reforça as relações conflituosas entre as classes, pelo que não se pode desconsiderar a força motriz dos dominados. Não há diante da lei uma condição de apatia ou inércia dos sujeitos-assujeitados. E não se edita impunemente uma lei. A correlação de forças permite vislumbrar que a lei não é um “fenômeno passivo, que existe apenas como uma mera consequência de uma dada formação social [...] É absolutamente necessário ter em conta o papel ativo da lei, estudando-a também através da experiência de resistência, pressão, rebelião e aquiescência dos dominados" (GEBARA, 1986, p. 1213). Delineando uma perspectiva futura de projeção - ideal e desejável - de variação na realidade, revela a consciência legal (MERRY, 1990, p. $5),{ }^{2}$ ou seja, como as pessoas percebem diferentemente uma específica lei. Como resposta vem a possibilidade de sua aceitação, influenciando as ações. Ou, de outra parte, pode moldar como discurso de resposta a instalação de mecanismos de resistência tal qual a desobediência ou o início de um movimento contrário de pressão, isto é, por vezes acarreta um efeito backlash como reação social e política.

No trânsito desse projeto político, nenhum campo permitiria melhor, então, identificar a presença da consciência legal pela credibilidade e da aceitação das leis, considerados como condicionantes de um registro simbólico introjetado nos sujeitos para que instale por meio dele esse controle social sem o uso da força ou da violência real externa com vistas a solucionar conflitos de interesses decorrentes da luta de classes, nos espaços de poder e por meio de direitos assegurados àqueles que não têm poder, do que o direito capitalista do trabalho. Supostamente acolhe-se a lei como um imperativo da paz social, apaziguador dos conflitos, ante a posição de sujeição.

A regulação jurídica do trabalho enquanto realidade concreta por meio das leis é tomado, então, como questão para análise da relação que 
se tem com as leis no Brasil, porquanto traduz a presença nem sempre impositiva e eficaz do seu conteúdo normativo e semântico, não obstante presente sua força coercitiva e a imperatividade em potência. A lei trabalhista pode se fazer presente como dissimulação, como ilusão nessa ordem jurídica capitalista de mercado; de todo modo marca sua existência, nem que seja pela referência exemplificadora de uma cultura do desrespeito.

Foi introjetado no imaginário popular, como um clichê ou uma frase feita, tido como incontestável porquanto naturalizado, o fato de que no Brasil existem leis "que não pegam". ${ }^{3}$ Inúmeros seriam os exemplos de leis trabalhistas que "não pegaram", de leis editadas "para inglês ver". Existem leis impossíveis de serem cumpridas, leis com comandos e sem sanção, leis de fiscalização irrealizável, leis meramente principiológicas. Um frenesi normativo. Costuma-se, como senso comum reproduzido, atribuir o desrespeito às leis a um excesso legislativo, ${ }^{4}$ ou à ignorância da existência de uma lei, ou ainda à baixa qualidade da produção legislativa e, talvez ao fato de que não se conectam com a realidade social, bem como à irrelevância do seu conteúdo.

A questão que inquieta a todos, porém, não se cinge ao fator meramente explicativo das razões econômicas, sociais e culturais que levam ao não cumprimento de uma lei, senão se, ainda assim, sem descurar do trânsito da política, é possível sustentar, no campo das representações, a lei como referencial de uma anotação simbólica ou, se em decorrência da desobediência e descaso, só restaria concluir por um deslizar no imaginário, o lugar próprio para a decepção, ante um declínio da força de lei.

A convivência em sociedade depende da introjeção em cada um de uma lei simbólica que se inscreva enquanto sujeito-cidadão, como chave para inclusão. Como pondera Brennan, "o simbólico coloca os seres humanos em relação uns com os outros e lhes dá um sentido do lugar que ocupam no mundo deles e a capacidade de falar e ser compreendidos pelos outros. 0 simbólico o faz possibilitando-lhes distinguirem-se uns dos outros, e pelo estabelecimento de uma relação com a língua" (BRENNAN, 1997, p.11). Portanto, se os homens não operassem psiquicamente dentro de um registro simbólico, não haveria condição de convivência mútua; estaríamos diante de um aglomerado de pessoas psicóticas vivendo lado a lado, contudo sem conviver ou travar laços sociais. 
A hipótese que gravita em torno da força de lei, então, é recortada pela possibilidade de ter sido subtraída da lei e do direito esse específico espaço de anotação do registro simbólico que, da sua parte, passaria a ser (ou está sendo) operado em algum outro lugar.

\section{O SILÊNCIO DAS PALAVRAS DA LEI, OU O DITO PELO NÃO DITO}

A opção por um pensamento crítico procura fazer aflorar o invisível, desvelar a ilusão, ou seja, escutar o dito pelo não-dito, que no caso é a correlação de forças traduzida tanto na edição quanto no cumprimento - ou não - das leis. A ausência de qualquer efetividade ou da aplicação de uma lei, por um lado não se constituem como situações identificáveis e, de outra, não consistem, ambas, como indiferente jurídico; 'dizem' algo, nem que seja a constatação da esquizofrenia ou o paradoxo do contraste entre a realidade formal da lei e a realidade da realidade das condições (FRENCH, 2001, p. 25). Pode-se constatar, ao menos, algum efeito colateral ou uma resposta de insurgência nascida da própria recusa ou rejeição; não responder positivamente com a observância é já uma resposta e, não há que se negar alguma geração de efeito.

Por certo que se a lei se fez realidade jurídica é porquanto algum interesse foi identificado e mereceu tradução em dispositivo legal; a linguagem, por palavras ou no silêncio, se impôs. Mas o silêncio não está somente no não dito como resposta, senão no dizer da própria lei para fazer crer que as narrativas de demandas foram ouvidas e acatadas, por exemplo. Não obstante, por alguma circunstância, algumas leis não têm o condão de dar respostas na concretude em se tratando de possibilidade de alterar, além da própria lei, a realidade referida.

No campo da dialética, nesse mundo permeado de complexidade, "o real não mantém as condições da sua existência senão numa luta, quer ela seja consciente quer inconsciente. A realidade que me surge num dado momento, uma fase da sua realização: esta é, de facto, um processo constante" (MIAILLE, 1979, p. 18). Rechaça-se a perspectiva de que todos cumprem todas as leis. 0 não cumprimento de leis é uma contingência da condição de humanidade em insurgência, nada 
obstante não desejável como pauta para traçar os limites da organização e o conduzir-se.

Como ressalta Souza, na forma de relacionamento com as leis pode-se supor um vetor que apontaria para uma "desobediência explícita" e outro para uma "desobediência travestida de obediência" (SOUZA, 1999, p. 129). No primeiro caso poderíamos pensar nas leis que não "pegam"; no segundo, as leis editadas "para inglês ver". De toda sorte, obedecer ou desobedecer é sempre um ato referido a algo, que mantém inafastavelmente a existência perceptível da lei. 0 não cumprimento poderá, se for o caso, introduzir uma identificação social por projeção que leva a um processo de desconstrução do lugar ocupado pela lei e pelo direito na organização coletiva do viver em sociedade, estabelecendo uma mudança no laço social, e assim merecedor de um olhar sobre alguns casos.

\subsection{LEI PARA INGLÊS VER}

A origem da expressão lei para inglês ver, a par de controvérsias, remonta o Bill Aberdeen, ${ }^{5}$ ou Slave Trade Suppression Act. Trata-se de uma lei aprovada em 8 de agosto de 1845 pelo Parlamento Britânico que autorizava a Marinha Real a interceptar e apreender qualquer navio que estivesse navegando nas águas do Oceano Atlântico e se dirigisse ao Império do Brasil se suspeito de traficar escravos, submetendo a tripulação às leis e jurisdição do Reino Unido. Fora o resultado da pressão exercida pelas forças abolicionistas: tratados firmados pelo Imperador brasileiro desde 1810 enquadravam o tráfico de pessoas em regime forçado de escravidão como crime de pirataria, devendo serem os escravos repatriados ao seu país de origem; o teor dos acordos não era observado.

Várias foram as discussões jurídicas em torno do direito internacional e de questões políticas decorrentes de incidentes diplomáticos que envolviam a imposição de regras de um país a outro, com alegado ferimento à soberania e independência do Império Brasileiro. 0 que é certo é que os tratados firmados pelo Brasil se revelaram uma grande falácia. Não por outra razão o Brasil foi instado a editar leis nacionais. Como resposta ao ingleses, para fazer ver que o Brasil estava empenhado em extinguir o comércio de escravos vindos da África, foi promulgada a Lei Feijó, de 7 de 
novembro de 1831, (BRASIL, 1831) que determinava que todos os escravos africanos trazidos ao Brasil a partir daquela data deveriam ser libertados e repatriados. Foi preciso aguardar até a Lei Eusébio de Queirós ${ }^{6}$, (BRASIL, 1850 ) de n. 581, de 4 de setembro de 1850, regulamentada pelo Decreto $n$. 731 , de 14 de novembro de 1850, que tornava ilegal o tráfico de escravos, para que pudesse ver sua eficácia comprovada.

Ocorre que o trabalho escravo era a base que organizava a economia brasileira; os traficantes não somente apoiavam, mas igualmente "sustentavam" - em todos os sentidos - o regime monárquico. Nunca se traficou tanto; o preço das "peças" se elevou no mercado por conta dos riscos de tal prática "comercial" e o Estado não mais controlava a entrada no país, deixando de ser exigido o pagamento de tributos. A lei "para inglês" ver traçou as marcas do futuro em torno de leis sem efetividade, muitas inclusive de caráter eminentemente demagógico, ${ }^{7}$ mas deixou rastros como um componente da realidade, gerando reflexos colaterais, no caso nocivos ao Estado, aos escravos e, porque não aos proprietários de escravos que tiveram que pagar um sobrepreço. Mesmo quando não é aplicada pela razão simples de ter sido editada para não gerar os efeitos pretendidos, na rede de normatividade alguma consequência é sentida, para além da confirmação de ser a lei, ela mesmo, a expressão da presença do Estado.

\section{Lei de locação de serviços de 1879}

Começamos mal. A primeira forma legal de intervenção do Estado na organização, estruturação e regulamentação de um mercado de trabalho livre fora a Lei de locação de serviços de 1879, Decreto n. 2827, de 15 de março de 1879 (BRASIL, 1879), que regulava a parceria agrícola, pecuária e a locação de serviços propriamente dita. Também conhecida como a Lei Sinimbu, ela foi uma "solução" dada em um "clima de gravidade e urgência” (LAMOUNIER, 1988, p. 9). Tratava-se de uma resposta às críticas dirigidas em torno das péssimas condições de tratamento recebido pelos imigrantes no período de trânsito do trabalho escravo para o trabalho livre e a falta de garantias para o cumprimento dos contratos sob égide das leis anteriores, de 1830 e 1837 (BRASIL, 1830; 1837). ${ }^{8}$ Teve sua vigência bastante reduzida temporalmente e pífia fora sua eficácia: 
Pois bem, constatada a lacuna (e liberada a bisbilhotice) não tardamos a intuir qual teria sido a razão do fracasso de muitos ânimos: em seguida à promulgação da Lei Sinimbu, um aviso circular enviado pelo Governo aos presidentes de província proibia a execução de alguns de seus mais importantes artigos; o que, na concepção da época, obstava considera-la em execução. E além do aviso, desenvolveu-se rápida e incisivamente na primeira metade da década de 80 uma forte oposição aos moldes de relação que a lei delineava, culminando com sua revogação em 1890.

\section{$[\ldots]$}

Ou seja, aparentemente a lei não teria saído do papel, era letra morta. Ora, se já existe um descrédito sobre o papel de uma legislação no Brasil do século passado, que aliás se estende ao atual, na crença de sua pouca ou nenhuma aplicação devido ao poder de mando dos fazendeiros, à ausência de um Estado e de um aparato policial, às longas distâncias, à falta de informação e outros, qual não seria a incredulidade frente ao papel de uma legislação que, pelos indícios, não teria extrapolado o impacto de sua aprovação nos órgãos institucionais? (LAMOUNIER, 1988, p. 13)

O Estado sempre se valeu de leis que se não pretendia cumprir; criou no imaginário social uma perspectiva de reconhecimento das narrativas dos sofrimentos e das demandas de interesses que já não era mais possível desconsiderar. E, embora praticamente não tenha tido aplicação, na exígua temporalidade em que permaneceu em vigência se constituiu como expressão da intervenção estatal na economia de mercado, com um marco regulatório que se posicionava em possibilidade de pressão e coerção sancionável do uso eventual da violência para se tornar realidade. Ademais, somente na hipótese de ausência de reconhecimento de interesses é que as demandas transitam; desta forma não há lei $100 \%$ cumprida, nem presença constatada de uma realidade disciplinada em lei em $100 \%$ dos casos. A lei, e assim os direitos, estão a pressupor sempre uma falta que constitui uma demanda, que nunca se realiza na totalidade.

\section{A CLT e o contrato em regime de tempo parcial}

A própria Consolidação das Leis do Trabalho quando veio a lume praticamente não era aplicada, sendo destinada a perto de $20 \%$ da classe trabalhadora. Em uma economia rural objetivou incentivar uma trans- 
formação fixando regras jurídicas que seriam observadas no processo de industrialização. Tendo sido promulgada "para inglês ver" (FRENCH, 1986, p. 35), os empregados foram "condenados a atuar no universo fraudulento criado pela CLT - que era manipulada contra os trabalhadores -, os militantes da classe trabalhadora e os sindicalistas, depois de 1943, subverteriam na prática a 'lei' existente por meio da luta para fazer da lei (como um ideal imaginário) uma realidade" (FRENCH, 1986, p. 72).

Mais recentemente, durante a primeira e principal década neoliberal no Brasil ('90) fora alterada a Consolidação das Leis do Trabalho por meio da Medida Provisória n. 1.709/98, de 06 de agosto de 1998, ${ }^{9}$ que recebeu multiplicidade de sucessivas reedições. Sob o argumento de modernizar o país, com um discurso de um novo "Renascimento", Incorporando o art. 58- $\mathrm{A}^{10}$ cria dentre outras medidas uma nova modalidade contratual. 0 contrato de trabalho em regime de tempo parcial é previsto para jornadas de trabalho pactuadas inferiores a 25 horas semanais, com a percepção de salários proporcionais, inovando com uma nova forma de fixação da extensão o número dias de férias - reduzido de 30 para 8 a 18 dias - e vedação de acordo de prorrogação para realizar horas extras. Os argumentos justificadores para adoção de um novo marco regulatório na contratualidade laboral foi apresentado pelo então Presidente da República Fernando Henrique Cardoso como resposta do Estado para superar a "era Vargas" e fazer face ao desemprego crescente, que orbitava em 2000, segundo o IBGE, os 15\% da População Economicamente Ativa, ou seja, 11.5 milhões de trabalhadores:

O presidente Fernando Henrique Cardoso disse que não se combate o desemprego com ações milagrosas e inexequíveis. "Não há milagre nessa matéria. $\mathrm{O}$ que há é trabalho e competência." (JORNAL FOLHA DE SÃO PAULO, 1998a) No pacote trabalhista que anunciou ontem, o governo incluiu uma medida provisória regulamentando o "trabalho a tempo parcial". Significa a possibilidade de contratos de jornada reduzida, com salário, férias, $13^{\circ}$ e outros benefícios proporcionais. Ou seja, menores. Justificativa oficial: aumentar a oferta de empregos, especialmente para os jovens que estudam e para as mulheres que têm filhos pequenos. (JORNAL FOLHA DE SÃO PAULO, 1998b)

Nem uma menção em torno das férias. Inovou para não mudar nada na contratualidade laboral. As razões não se justificavam, pois desde sempre 
foi possível a contratação para jornadas de trabalho inferiores a 44 horas semanais, dentro do limite máximo imposto pela ordem constitucional, observando-se sempre a proporcionalidade na remuneração. Portanto, essa tipologia contratual era desnecessária como opção e a impossibilidade de pactuação de acordos de prorrogação da jornada não atendeu ao interesse do capital de extrair mais valia com a intensificação do trabalho.

Ademais, a presença de dois regimes diferenciados de cálculo e extensão das férias cria uma discriminação insustentável para os empregadores que buscam o zelo dos seus empregados na entrega da força de trabalho. E o direito à desconexão, presente nas interrupções do trabalho pela concessão das férias, não raras vezes vai ao encontro do interesse do capital em controlar o fluxo da produção para diminui o prejuízo com o capital imobilizado. Necessário acrescentar o fato de que o período de férias é usufruído para recomposição da força física e equilíbrio emocional, prevenindo inclusive eventuais acidentes de trabalho.

Introduziu-se mais uma lei para inglês ver, porquanto inócua como incremento de postos de trabalho. ${ }^{11} \mathrm{~A}$ lei veio ao mundo para que se pudesse crer - imaginário social - na ideia de que o Estado (DRAIBE, 2003) ${ }^{12}$ onipotente não permanece inerte ante o impacto negativo do desemprego na classe trabalhadora. Estaria agindo com medidas para combate-lo, fomentando a criação de novos empregos especialmente aqueles destinados a segmentos mais vulneráveis no mercado de trabalho, como mulheres que realizam dupla jornada e jovens estudantes que devem atender atividades educacionais.

O desemprego não se enfrenta com leis ou com o Direito, que não se situa como a causa e, portanto, não será a solução, senão com políticas públicas sobretudo macroeconômicas. Neste trilhar, ante o fato da absoluta desnecessidade de tal medida legal, que não espelhava ou atendia as demandas da sociedade, a lei não "pegou”. 0 desemprego não reduziu, nem os empregadores e empregados fizeram opções por tal possibilidade normativa. Entretanto, sustentou a perspectiva de que a lei tudo pode e, além da onipotência, principalmente, chancelou a flexibilização de direitos como alternativa de resposta estatal, traço que marcou o governo FHC. 0 desmantelamento de direitos, fragmentando as relações jurídicas, é um processo lento e contínuo. 


\subsection{LEIS QUE "NÃO PEGAM"}

Inúmeros são os exemplos, também, de leis trabalhistas que não encontram na realidade social qualquer receptividade. Não se está diante de uma constatação de descumprimento somente por aqueles a quem a regra jurídica se destina; o descaso para com a dicção normativa é mais ampla, abarcando inclusive, em algumas hipóteses, até mesmo o Estado, pelo Poder Judiciário, a quem caberia, em última instância, fazer valer o seu conteúdo.

A lei não se faz presente como uma factível e desejável resposta às demandas de interesses ou solução para os conflitos, demonstrando que, não obstante em geral a lei se apresente como o resultado de uma correlação de forças na sociedade, nas hipóteses em que apenas se constitui como mais uma propositura decorrente do espaço democrático das representações políticas, a ausência de resposta por parte daqueles a quem a lei se aplica é já uma resposta.

\section{O contrato temporário de trabalho}

O contrato temporário de trabalho designa o marco da flexibilização no Direito do Trabalho, albergando as apostas na adoção da ideologia neoliberal para enquadrar os direitos dos trabalhadores como expressão de custos de produção e assim reduzi-los com o objetivo de almejar maior competitividade para as empresas no espaço de um mercado mundializado (RAMOS, 1999, p. 19).

Após o Sindicato dos Metalúrgicos de São Paulo, filiado à Força Sindical, ter pactuado um instrumento normativo para a categoria com o Sindicato Nacional da Indústria de Autopeças (Sindipeças), seguido por outra negociação coletiva acordada entre o Sindicato dos Metalúrgicos do ABC com a Volkswagen, visando redução de custos, dado o fato político o Governo Federal encaminhou um projeto de lei no mesmo sentido, por meio da Mensagem n. 257, de 28 de março de 1996, para generalizar a opção.

A proposta veio respaldada em uma argumentação de combate ao desemprego mediante redução de direitos para diminuir o dito "custo Brasil”, apontado como sendo da ordem de 102,06\% (RAMOS, 1999, p. 
111-112). A Lei n. 9.601, de 21 de janeiro de 1998, cria uma modalidade contratual de trabalho por tempo determinado fora das hipóteses previstas de modo restritivo no art. 443 da Consolidação das Leis do Trabalho, mediante acordo ou convenção coletiva de trabalho, com redução de encargos na hipótese de acréscimo do número de empregados. A contribuição para o Fundo de Garantia por Tempo de Serviço passa de 8\% para 2\%.

Ocorre que os custos são projetados no preço final do produto e, ademais, dentre os fatores de produção o preço pago pela força de trabalho, comparando com o valor de outros países, não é tão significativo. Como não impactaria positivamente o suposto "custo Brasil", "não pegou”, mas manteve-se na trajetória de implementação de um projeto de flexibilização de direitos.

\section{A Convenção 132 da Organização Internacional do Trabalho}

Por meio do Decreto de Promulgação n. 3.197, de 5 de outubro de 1999, a Convenção n. 132, da Organização Internacional do Trabalho passou a integrar o ordenamento jurídico infraconstitucional, com uma nova disciplina para o direito às férias, quase duas décadas após ter o Congresso Nacional aprovado, por meio do Decreto Legislativo n. 47, o que ocorreu em 23 de setembro de 1981.

0 tratado multilateral foi concluído em Genebra em 24 de junho de 1970, com início de vigência internacional em 30 de junho de 1973.

Dentre as alterações encontra-se a necessidade de uma consulta prévia pelo empregador ao empregado quanto a melhor data da fruição do direito (art. 10) e um novo período de concessão, mais alargado do que o disposto até então na Consolidação das Leis do Trabalho (art. $9^{\circ}$ ). Desta forma, não é possível concluir que o absoluto descaso para com a nova disciplina regulatória resulta do fato de que se introduziu uma normativa mais favorável ou desfavorável a um ou outro sujeito da contratualidade. Ademais, as normas posteriores que tratam da mesma matéria, em um mesmo patamar de hierarquia, revogam disposições vigentes, dada a imediata aplicação na lei posterior.

Entretanto, a lei não "pegou"; os empregados e empregadores não aplicam seus dispositivos, os advogados não a invocam em suas petições 
e o Poder Judiciário não enfrenta a necessidade de sua observância, ainda que em decorrência de especificidade do processo trabalhista conste como requisito da petição inicial apenas uma breve exposição dos fatos, cabendo à autoridade jurisdicional fazer impor a observância do direito posto.

A absoluta ausência de eficácia da norma poderia ser resultado do desconhecimento, embora a ninguém seja dada a possibilidade de invocar ignorância para não cumprimento; revela, a bem da verdade, a posição de incredulidade quanto a força normativa de fontes de origem internacional, tal como atos multilaterais oriundos da Organização Internacional do Trabalho, mesmo que albergados por Decretos Legislativos e de Promulgação.

\section{A LEI COMO A REFERÊNCIA AO OUTRO QUE NOS REFERENCIA}

Dentre as marcas da contemporaneidade se situa a substituição no direito, sobretudo, mas não a ele restrito, de uma racionalidade jurídica da legalidade para acolher uma racionalidade econômica da eficiência. A lei, a legalidade, podem perder seu papel de referência que nos introduz como cidadãos na sociedade.

0 ato de "obedecer" às leis depende, por um lado, do espaço e papel que destinamos ao direito enquanto forma regulatória organizativa da sociedade, diretrizes das nossas condutas e solução dos nossos conflitos.

Se as nossas condutas estão pautadas pela análise econômica da eficiência, uma mudança epistemológica impele para a alteração da anotação do simbólico. Em decorrência da introdução da ideologia neoliberal, a lógica dos custos dimensiona o agir em conformidade ou não a tais marcos regulatórios, segundo uma apreciação da contingência do resultado (fins), não importando os meios. No caminhar da racionalidade jurídica da legalidade, alguém se submete às regras, cumpre a diretriz normativa e assume os resultados, mesmo que não desejados. Na racionalidade econômica da eficiência alguém pauta a conduta pelo resultado desejado e a ação será determinada pelo andar mais eficiente, nem que para tanto tenha quer mudar as regras do jogo ao jogar, porquanto afinal, como homo ludens (HUIZINGA, 2001, p.87-100), só se pensa em ganhar a qualquer custo. 
Os custos sociais e econômicos, bem como os jurídicos, de observar e efetivar um dispositivo de lei se traduzem em uma escolha nem sempre racional, isto é, de forma consciente ou inconsciente a escolha vem pautada pelos efeitos que serão atribuídos às decisões.

\section{PARA CONCLUIR COM A ANOTAÇÃO SIMBÓLICA DO PODER DA VIOLÊNCIA}

Em um sistema de referência legada pela cultura que antecede ao nascimento do sujeito, poder-se-ia intuir que a lei obedecida é a lei temida, isto é, a lei que tem potência de imposição de limite ditado pelas autoridades aparelhadas para que venham a ser cumpridas. Desta forma, leis "não pegaram" porquanto ausente o Estado. Mas antes de tudo é a lei introjetada a partir da inscrição de uma anotação simbólica no sujeito, como um dos registros essenciais da realidade humana: obedeço à lei porquanto identifico nela a legitimidade da fixação de normas que entendo devo observar e a situo no lugar da autoridade à qual me submeto voluntariamente. A própria referência e o reconhecimento da submissão à autoridade da lei já seria (ou deveria) ser suficiente para sua observância.

De toda sorte, não se pode concluir no sentido de que as leis no Brasil não sejam cumpridas pela constatação de seu descumprimento por uns ou alguns. Mister repisar que não se deve descurar do fato de que é da ordem da impossibilidade que todos cumpram todas as leis; seria uma recusa da realidade, que nos remeteria ao lugar da exceção. Ademais, como pondera Derrida, "existem, certamente, leis não aplicadas, mas não há lei sem aplicabilidade, e não há aplicabilidade ou 'enforceability' da lei sem força, quer essa força seja direta ou não, física ou simbólica, exterior ou interior, brutal ou sutilmente discursiva - ou hermenêutica -, coercitiva ou reguladora, etc" (DERRIDA, 2010, p. 9).

Em princípio toda lei, enquanto ato que exprime violência, tem seu caráter de coercibilidade, de interdição, de imperatividade, sua força (enforcement), se mantendo dentro dessa anotação que revela em cada um a ordem simbólica imposta: “A existência de uma lei, mesmo quando não aplicada, é sempre um mecanismo de pressão e coerção em potencial que, se necessário, pode sancionar o uso da violência" (GEBARA, 1986, 
p.23). No pior dos casos, pura violência instituinte, de exceção, do Estado ante o sujeito-assujeitado. Pode a qualquer tempo ser invocada e imposta, eis que o limite está já registrado na constituição do aparelho psíquico, desde que seja reconhecida como autoridade. É o limite de um terceiro ao projeto de gozar a qualquer preço ante a ausência de regras ou de introduzir minhas próprias regras no jogo da vida.

0 direito moderno retira dos sujeitos jurídicos individuais todo o poder, pois "o interesse do Direito pela monopolização do poder em face da pessoa individual não se explica pela intenção de garantir os fins do Direito, mas antes o próprio Direito" (BENJAMIN, 2012, p. 63). 0 poder, que tem for função instituir ou manter o direito, é um poder ameaçador, consubstanciado pela violência instituída, empregada como meio para fins jurídicos, isto é, para submissão das pessoas às leis:

É que a função do poder como violência na instituição do Direito é dupla, na medida em que essa instituição se propõe ser aquilo que se institui como Direito, como seu fim, usando a violência como meio; mas, por outro lado, no momento da aplicação dos fins em vista como Direito, a violência não abdica, mas transforma-se, num sentido rigoroso e imediato, em poder instituinte do Direito, na medida em que estabelece como Direito, em nome do poder político, não um fim livre e independente da violência, mas um fim necessária e intimamente a ela ligado. A instituição de um Direito é instituição de um poder político e, nesse sentido, um ato de manifestação direta da violência. (BENJAMIN, 2012, p.77)

0 projeto coletivo, como quer Lebrun (LEBRUN, 2009, p.10), deve "ser sustentado concretamente por aquele que tem o direito de impor, em nome do bem comum - a partir da autoridade que lhe confere o lugar reconhecido como prevalente e coletivamente aceito". 0 esfacelamento ou a diluição da legitimidade desse lugar, levaria à paralisia do projeto coletivo e à lei do mais forte. Há um lugar para a exceção. A transgressão pelo não cumprimento da lei poderia ser a recusa ao princípio da violência que o direito institui, para fazer nascer um outro e novo direito. Esse novo direito poderia ser o direito sem mediação, o direito da esfera do diálogo, do entendimento, do consenso, da conciliação, do negociado.

É, de certa forma, o que se vislumbra com propostas de combate ao direito do trabalho "rígido", "superprotetor", para flexibilização do 
direito do trabalho, com a ideia de que conciliar é bom, com a perspectiva (mesmo sem alterar a lei) de que se deve introduzir a primazia do negociado sobre o legislado. No entanto, ainda assim e ainda aqui não se pode prescindir totalmente da violência do poder da lei pelo Estado, até porquanto a anomia significará a autotutela de luta de classes que se quer ocultar travestindo-a de colaboração. As leis estão ainda presentes diante da sua função de instituidora e mantenedora do direito. Um mundo sem leis é um mundo da utopia. A constatação do descumprimento das leis ou a indiferença ante elas, não as afastam como marca da autoridade e violência nos sujeitos.

É o outro dentro de nós que nos impele a reconhecer a autoridade e submeter-se a elas. As leis na sua dimensão social exprimem sempre a correlação de forças na sociedade e, portanto, ao mesmo tempo em que exprimem o desejo de domínio, se constituem como pura manifestação de expressão de força. Eventualmente as expectativas de solução dos conflitos se constituem como o produto dessa sociedade: o pacto não celebrado, o silente acordado, o imposto e mascarado ou o rompido e não dito.

Diante de leis que "não pegam" ou de leis editadas "para inglês ver", interessa menos compreender e posicionar-se em torno de distintas revelações: se a lei é um conceito interpretativo e, dentre outros, os juízes devem decidir o que é a lei, atitude auto-reflexiva dirigida à política, como pretende Dworkin (DWORKIN, 2007), ou se as pessoas se posicionam em obediência aos mandamentos legais como um espaço de participação popular, como pontua Hart (HART, 1986); não importa. Embora reconheçam a insuficiência da mera abstração teórica e, assim, sua dimensão social (BARRETO, 2010, p. 5), ambos se mantêm no paradigma mítico da modernidade e na filosofia da consciência. É preciso um passo a mais.

O registro simbólico não se reduz à constatação de sua observância, à verificação do cumprimento de uma dada e específica norma inserta na lei. Não se trata, no caso, de extrair da constatação um simbolismo, tomado no sentido de projetar uma representação entificada em símbolo para exprimir uma crença ou transmitir uma tradição (ROUDINESCO; PLON, 1998, p. 715).

É de se rejeitar, ademais, a ideia reducionista da lei (ou de sua existência, validade e eficácia) somente como um mito (BARTHES, 1982), 
que é o que é dito no lugar do que não pode ser dito, do não-dizível, o intocável e não verificável, o fundante em torno do qual construímos nossas crenças, o lugar do inacessível. Paul Ricoeur, invocando Mircea Eliade, sustenta que o mito, para cultura, seria um "racconto sul origini", isto é, uma espécie do gênero narrativo (RICOEUR, 2014). Mito é recebido pela tradição e "considerati dai membri del gruppo, senza altra garanzia che la fede di coloro che li trasmetonno" (RICOEUR, 2014, p. 9). Sendo explicativo do evento de fundação de uma cultura, o mito não comporta comprovação. Ora, pode-se e se deve colocar a lei em julgamento, ao crivo sobretudo da sua adequação à Constituição, verificando igualmente o atendimento dos parâmetros prévios que definem as formalidades que deve observar, por exemplo. É imperioso reconhecer que não há um caráter mítico da lei; ela é em si materializável e não uma narrativa. A lei não é mito, mas se sustenta em um.

É necessário, outrossim, refutar o enquadramento explicativo dos motivos pelos quais leis "não pegam" ou são trazidas a lume "leis para inglês ver", criticamente, como um discurso ideológico do texto que "mascara ou falseia a realidade ou a consciência" e, desta forma, se constitui como mero instrumento de dominação, alienador. A realidade do descumprimento não é um dado em si que possa ser desvelado, uma verdade oculta pela linguagem como uma essência apreensível que, uma vez superada a aparência que introduziu a ilusão, mostraria o escondido. A realidade "revelada", a narrativa que traduz um discurso "ideológico" é a própria referência a esse clichê de que as leis não são cumpridas no Brasil.

0 real concreto depurado da ideologia (se é que seria factível apreender essa realidade) seria demais para todos. Ideologia revelada como fenômeno ambíguo, com um papel construtivo e outro destruídor (RICOUER, 2015, p.15). Retrataria a mudança do laço social; o enfraquecimento do papel de autoridade do Estado, a desconfiança da lei como função. Se, por um lado, não há neutralidade pasteurizada do mal, por outro não há "a verdade dos fatos", eis que para além da consciência tem-se um lugar, ocupado pelo outro desconhecido que nos identifica e marca sua presença. A lei, enquanto espaço inafastável de ideologia materializada, é sempre e sempre será enganosa. Não por outra razão nossa razão jurídica não nos permite colocar uma cláusula de abertura para deixar de aplicar uma 
lei pelo seu desconhecimento, pela incompreensão do seu sentido, ou revogar uma lei pelo desuso, por exemplo. Depositamos sempre, nela, a crença na possibilidade de mudança, um ideário a ser cumprido, mesmo que personifique o uso da força, a manifestação da violência, a hegemonia da classe dominante, o Estado.

Importa reconhecer para além da função - e mais do que a eficácia simbólica da lei como um "elemento da cultura (crenças, mitos, ritos) e de lhes atribuir um valor expressivo" em si (ROUDINESCO; PLON, 1998, p. 714), ou seja, que representa essa inscrição e registro simbólico, uma posição. 0 esfacelamento da legitimidade do lugar que ocupa e a deterioração do espaço de autoridade que lhe é atribuída (posições), tomando-a como uma anotação da ordem da indiferença - pelo descumprimento - pode levar à anomia e à violência real: "à situação em que se encontram os indivíduos quando as regras sociais que guiam suas condutas e suas aspirações perdem seu poder, são incompatíveis entre si ou quando, minadas pelas mudanças sociais, devem ceder lugar a outras" (LEBRUN, 2009, p. 16).

Um lugar (posição) de registro de mediação, na adesão de uma coletividade em um dado sistema ou ordem estruturada como linguagem depende desse simbólico da lei e de uma referência a uma externalidade que personifique a autoridade. A lei, qualquer que seja, funda (função) a ordem na qual está inserido o sujeito, em nome de um referencial introduzido, registrado pela cultura que antecede a todos e à qual fomos imersos pelo nascimento, promulgando por um terceiro, que impõe sua presença, o lugar ocupado (LAPLANCHE; PONTALIS, 1992, p. 481). Se não for ela, a lei, será outro; poderá ser o mercado, o capital, o consumo.

Quando narramos e acreditamos que lei ocupa o lugar do imaginário, "não pegando" ou quando se revela como uma aposta para "inglês ver", estamos diante de um projeto de declínio da ordem simbólica, ou seja, uma tentativa de destituição do lugar que exprime e se coaduna com o registro de cada um, desautorizando-a, com a propagação aos ventos que não é preciso observá-las, que leis não são aplicadas. Ocorre que é exatamente a lei que se coloca como o limite ao anseio de que todo desejo deva ser satisfeito, de que toda reivindicação deva ser atendida. Assim a carta enviada envia como mensagem: tudo, agora, é possível. Talvez a conclusão nos levaria a pensar que na contemporaneidade o declínio 
da autoridade da lei acarreta o exercício dessa função limitadora pelo mercado, na ordem capitalista. A mutação do laço social se manifestaria para substituição do Estado, em uma sociedade que se pretende pautada pela completude, em recusa à autoridade no público e no estatal, abrindo as portas para um gozo a qualquer preço e para a predominância do individual sobre projetos coletivos de vida em comunidade. Eis o projeto de declínio da função e da posição ocupada no registro simbólico, que ainda se faz presente como ato de violência.

Se leis "não pegam" ou são apenas "para inglês ver" haveria alguma e qual então seria sua dimensão social ou seu papel dinâmico na formação social? Serviriam para qual projeto político ou para quem? Trata-se de mero cinismo, ou manifestação de uma ideologia que fantasia e mascara a mentira que é a ideia de que leis não são cumpridas? Certamente a disseminação desse lugar comum de que leis no Brasil não são cumpridas atuam para enfraquecer a anotação do registro simbólico (no sentido não psicanalítico) da violência pela imperatividade e coerção próprias das regras jurídicas e do lugar (posição) ocupado pelo direito e pelo Estado. Ao introjetarmos e reproduzirmos o bordão nos tornamos cúmplices e atores do enfraquecimento do projeto coletivo moderno de inclusão pela autoridade da lei, mesmo que seja expressão da violência (função), eis que passaria a valer a lei interna de cada um e, desta forma, a do mais forte, apontando para a ausência de limites ao desejo de gozar a qualquer preço. Recusar a força da lei pode ser uma forma de rejeição à violência, no entanto introduzirá no cotidiano das relações outra forma de violência, a real.

A lei.... ora a lei..., já dizia Getúlio Vargas.

\section{NOTAS}

1 Irrelevante para a presente análise se o sentido atribuído ao vocábulo lei, enquanto fonte de direito, é tomado no sentido da expressão e resultado da função legislativa e, portanto, se correlata ou não ao critério distintivo de uma certa formalidade ou conteúdo material; tampouco interessa verificar diferenças entre direito legislado e escrito ou direito consuetudiário e não escrito.

2 "The law consists of a complex repertoire of meanings and categories understood differently by people depending on their experience with and knoledge of the law [...] The ways people understand and use lau I term their legal counsciousness. Counsciousness, as I am using the term, is the way people conceive of the 'natural'and norma way of doing things, their habitual patterns of talk and action, and their commonsense understanding the world. The consciousness, I am describing ins not only the realm of deliberate, intentional action but also that os habitual action and practice". MERRY, Sally Engle. Getting justice and getting even: legal consciousness 
among working-class americans. Chicago; London: The University of Chicago Press, 1990. p. 5 Disponível em: https://books.google.com.br/books?id=AEFPURuB-GoC\&pg=PR4\&lpg=PR4\&d $\mathrm{q}=$ MERRY,+Sally+Engle.+Getting+justice+and+getting+even:+legal+consciousness+among+wo rking-class+americans.+Chicago+:+University+of+Chicago+press, $+1990 \&$ source=bl\&ots=ENfa 3G8Lp3\&sig=8kfwOIbaEfznS6G5InzbQgekIVI\&hl=pt-BR\&sa=X\&ved=0ahUKEwio7vTaw_3PAhU JkZAKHQxrDGAQ6AEIKzAC\#v=onepage\&q=MERRY\%2C\%20Sally\%20Engle.\%20Getting\%20 justice $\% 20$ and $\% 20$ getting\%20 even $\% 3$ A $\% 20$ legal $\% 20$ consciousness $\% 20$ among\%20workingclass $\% 20$ americans. $\% 20$ Chicago $\% 20 \% 3$ A $\%$ 20University $\% 20$ of $\% 20$ Chicago $\% 20$ press $\% 2$ C $\% 20$ 1990\&f=false Acesso em: 27out2016. Citado ainda por FRENCH, 2001, p. 60-61.

3 A FGV criou um índice de percepção do cumprimento da lei para discutir o grau de efetividade do Estado de Direito no Brasil, mensurando como o brasileiro percebe o comportamento da sociedade em relação à obediência às leis. São dois subíndices: um de percepção e outro de comportamento. 0 subíndice de percepção foi construído a partir de quatro indicadores: (i) de instrumentalidade, para mensurar a percepção das perdas associadas ao descumprimento da lei - sanções; (ii) de moralidade, para medir a percepção sobre o quanto é certo ou errado realizar determinada conduta que esteja em desconformidade com a lei; (iii) de controle social, que analisa a percepção de reprovação social a determinados tipos de comportamento de descumprimento da lei e, por fim, o último, (iv) de legitimidade, para aferir a percepção sobre a obediência à lei e às ordens de autoridades que devem fazer com que a lei seja cumprida. 0 subíndice de comportamento foi adotado por um indicador de conformidade com a lei, isto é, para verificar a a frequência com que os entrevistados declaram ter realizado ações descumpridoras de leis. De 0 a 10 , no $1^{\circ}$ trimestre de 2015, o IPCLBrasil foi 7,0, sendo aferido em 8,5 para comportamento e 6,6 para percepção. Dentre as conclusões está a de que a possibilidade de se desrespeitar a lei é inversamente proporcional à probabilidade de ser punido, ou seja, quanto menor é a probabilidade identificada pelo entrevistado de ser punido, maior é a frequência de realização de condutas de desrespeito à lei. Disponível em:http://bibliotecadigital.fgv.br/dspace / bitstream/handle/10438/13729/Relat\%C3\%B3rio_IPCLBrasil_1\%C2\%BA\%20Trimestre\%20 2015.pdf Acesso em: 27out2016.

4 Diz-se que entre 2000 e 2010 foram editadas 75.517 leis, sendo 68.956 estaduais e 6.561 federais. Disponível em: http://bibliotecadigital.fgv.br/dspace/bitstream/handle/10438/13729/ Relat\%C3\%B3rio_IPCLBrasil_1\%C2\%BA\%20Trimestre\%202015.pdf Acesso em 20out16.

5 George Hamilton-Gordon, Lord Aberdeen, então Ministro das Relações Exteriores do Reino Unido, foi o propositor da lei inglesa. 0 Reino Unido havia abolido definitivamente a escravidão nas suas colônias desde 1833, sendo o tráfico proibido desde 1807.

6 Ministro Eusébio de Queirós Coutinho Matoso Câmara.

7 A Inglaterra, entretanto, apreendeu centenas de navios negreiros em decorrência do Aberdeen Act.

80 trabalho era mais próximo de um modelo servil, de trabalho forçado, do que um trabalho livre; a garantia do cumprimento dos contratos se dava, conforme dispositivos legais, pela prisão.

9 Foram sucessivas reedições, com alteração do número da MP: após a MP 1.709-4/98 tomando o número MP 1.779-6/99; depois da MP 1.779/99-11, se tornou como MP 1.879-12/99; depois da MP 1.879-17/99 foi reeditada como MP 1.952-18/99; depois da MP 1.952-31/00 foi reeditada como MP 2.076-32/00; depois da MP 2.076-38/01 foi reeditada como MP 2.164-39/01; a última reedição é da MP 2.164-41/01. Disponível em: http://legis.senado.gov.br/legislacao/ ListaPublicacoes.action?id=68244\&tipoDocumento=DEC\&tipoTexto=PUB Acesso em: 23 set2016.

10 Consolidação das leis do trabalho. Art. 58-A. Considera-se trabalho em regime de tempo parcial aquele cuja duração não exceda a vinte e cinco horas semanais.

11 Idêntica situação pode ser verificada com a Lei n. 9609/98, que trata do trabalho voluntário.

12 Sobre as décadas de '80 e '90, ver: DRAIBE, Sonia. A política social no período FHC e o Sistema de proteção social. Tempo social. N. 15, n. 2. São Paulo, nov.2003. Disponível em: http://dx.doi. org/10.1590/S0103-20702003000200004 Acesso em: 18out2016. 


\section{REFERÊNCIAS}

ARON, Raymond. 0 marxismo de Marx. São Paulo : Arx, 2003.

ASCENSÃO, José de Oliveira. 0 direito: introdução e teoria geral: uma perspectiva luso-brasileira. 11.ed. Lisboa : Almedina, 2011.

BARRETO, Vicente de Paulo. 0 fetiche dos direitos humanos e outros temas. Rio de Janeiro : Lumen Juris, 2010.

BARTHES, Roland. Mitologias. 5. ed. São Paulo : Difel, 1982.

BENJAMIN, Walter. Sobre a crítica do poder como violência. In: 0 anjo da história. Belo Horizonte : Autêntica, 2012, p.59-82.

BOURDIEU, Pierre. O poder simbólico. 7. ed. Rio de Janeiro : Bertrand Brasil, 2004.

BRENNAN, Teresa. Introdução. Para além do falo: uma crítica a Lacan do ponto de vista da mulher. Rio de Janeiro : Record; Rosa dos Ventos, 1997.

BRASIL. LEI DO IMPÉRIO. LEI DE LOCAÇÃO DE SERVIÇOS DE 1830. LEI DE 13 DE SETEMBRO DE 1830. Disponível em: http://www2.camara.leg.br/legin/fed/ lei_sn/1824-1899/lei-37984-13-setembro-1830-565648-publicacaooriginal89398-pl.htmlAcesso em: 23set.2016.

BRASIL. LEI DO IMPÉRIO. LEI DE LOCAÇÃO DE SERVIÇOS DE 1837. LEI 108 DE 11 DE OUTUBRO DE 1837. Disponível em: http://legis.senado.gov.br/legislacao/ ListaTextoIntegral.action?id=62158\&norma=78042 Acesso em: 23set. 2016 .

BRASIL. LEI DO IMPÉRIO. LEI DE LOCAÇÃO DE SERVIÇOS DE 1879. DECRETO 2.827 DE 15 DE MARÇO DE 1879. Disponível em: http://www2.camara.leg.br/ legin/fed/decret/1824-1899/decreto-2827-15-marco-1879-547285-publicacaooriginal-62001-pl.html Acesso em: 23set.2016.

BRASIL. LEI DO IMPÉRIO. LEI EUSÉBIO DE QUEIRÓS. LEI 581 DE 4 DE SETEMBRO DE 1850. Disponível em: http://www.planalto.gov.br/ccivil_03/leis/LIM/ LIM581.htm Acesso em: 23set2016.

BRASIL. LEI DO IMPÉRIO. LEI FEIJÓ. LEI DE 7 DE NOVEMBRO DE 1831. Disponível em: http://www2.camara.leg.br/legin/fed/lei_sn/1824-1899/lei-37659-7-novembro-1831-564776-publicacaooriginal-88704-pl.html Acesso em: 23set2016.

DERRIDA, François. A força da lei. São Paulo : Martins Fontes, 2010. 
DRAIBE, Sonia. A política social no período FHC e o Sistema de proteção social. Tempo social. v. 15, n. 2. São Paulo, nov.2003. Disponível em: http://dx.doi. org/10.1590/S0103-20702003000200004 Acesso em: 18out2016.

DWORKIN, Ronald. 0 império da Lei. 2. ed. São Paulo : Martin Fontes, 2007.

FRENCH, John. Afogados em leis e famintos por justiça: a CLT e a cultura política dos trabalhadores brasileiros. São Paulo : Perseu Abramo, 2001.

FUNDAÇÃO GETÚLIO VARGAS. FGV DIREITO SP. RELATÓRIO IPCLBRASIL. Disponível em:http://bibliotecadigital.fgv.br/dspace/bitstream/handle/10438/13729/Relat\%C3\%B3rio_IPCLBrasil_1\%C2\%BA\%20Trimestre\%20 2015.pdf Acesso em: 27out2016.

GEBARA, Ademir. 0 mercado de trabalho livre no Brasil (1871-1888). São Paulo : Brasiliense, 1986.

HART, Herbert. 0 conceito de direito. Lisboa : Fundação Calouste Gulbenkian, 1986.

HUIZINGA, Johan. Homo ludens: o jogo como elemento da cultura. São Paulo : Perspectiva, 2001.

Jornal Folha de São Paulo. 06ago1998a. Disponível em: http://www1.folha. uol.com.br/fsp/brasil/fc07089809.htm Acesso em: 30set2016.

Jornal Folha de São Paulo. 7ago1998b. Disponível em: http://www1.folha.uol. com.br/fsp/opiniao/fz07089805.htm Acesso em: 30set2016.

LAMOUNIER, Maria Lúcia. Da escravidão ao trabalho livre: a lei de locação de serviços de 1879. Campinas : Papyrus, 1988.

LAPLANCHE, J.; PONTALIS, J-P. Vocabulário da psicanálise. São Paulo : Martins Fontes, 1992.

LEBRUN, Jean-Pierre. Clínica da instituição: o que a psicanálise contribui para a vida coletiva. Porto Alegre : CMC editora, 2009.

MARX, Karl. 0 capital. 20. ed. Rio de Janeiro : Civilização brasileira, 2002, l.1, v.1.

MERRY, Sally Engle. Getting justice and getting even: legal consciousness among working-class americans. Chicago : University of Chicago press, 1990. Apud FRENCH, John. Op. cit., p. 60-61.

MIAILLE, Michel. Uma introdução crítica ao Direito. Rio de Janeiro : Pax, 1979. 
MERRY, Sally Engle. Getting justice and getting even: legal consciousness among working-class americans. Chicago; London: The University of Chicago Press, 1990.

NEVES, Marcelo. A força simbólica dos direitos humanos. Revista eletrônica de Direito do Estado, n.4, out.-dez2005. Disponível em: http://www.direitodoestado.com/revista/rede-4-outubro-2005-Marcelo\%20Neves.pdf Acesso em: 27out2016.

RAMOS, Alexandre. Contrato temporário de trabalho: combate ao desemprego ou redução do custo da força de trabalho? São Paulo : LTr, 1999.

RICOEUR, Paul. I miti della ragione e della salvezza. Roma : Castelvecchi, 2014.

A ideologia e a utopia. Belo Horizonte : Autêntica, 2015.

ROUDINESCO, Elisabeth; PLON, Michel. Dicionário de psicanálise. Rio de Janeiro ; Zahar, 1998.

SOUZA, Mériti de. A experiência da lei e a lei da experiência. Ensaios sobe práticas sociais e subjetividades no Brasil. São Paulo : Fapesp; Rio de Janeiro: Revan, 1999.

STUTCHKA, Piotr. Direito de classe e revolução socialista. 2.ed. São Paulo : Instituto José Luís e Rosa Sundermann, 2001, p.89.

Recebido em: 29-10-2016

Aprovado em: 16-5-2017

\section{Aldacy Rachid Coutinho}

Doutora e mestre em Direito pela Universidade Federal do Paraná (UFPR); especialista em Antropologia Filosófica pela UFPR; professora associada de Direito do Trabalho da UFPR; líder do Grupo de Pesquisa "Trabalho Vivo". Integrante da RENAPEDTS. E-mail: aldacycoutinho@gmail.com

Universidade Federal do Paraná. Setor de Ciências Jurídicas. Departamento de Direito Privado.

Praça Santos Andrade 50 - 3o andar. Centro. 80020-240 - Curitiba, PR - Brasil 